\title{
Modification of energy density with inhibitors of carbohydrate and fat digestion
}

\author{
BY RODNEY H. TA YLOR \\ Professorial Medical Unit, Royal Naval Hospital, Haslar, Gosport, Hampshire PO12 2 AA
}

Dietary energy density is determined by the composition of the diet and the availability of the energy when the diet is consumed. An overall simplification of the energy content of the diet can be misleading because the natural associations of nutrients in foods influence the amounts taken. Methods of food preparation, dietary habit and satiety also influence choice and energy availability. Fat and alcohol are energy dense but their intake is limited in a balanced diet. However, fat and protein are commonly associated in many foods so a high protein intake may be associated with a high intake of energy-dense fat. Foods composed mainly of carbohydrate are not usually associated with a high fat content and the availability of their energy may be further reduced by the effects of dietary fibre. This can act in two ways, first in unrefined foods by slowing the rate of digestion of the carbohydrate and second, by slowing the diffusion of the products of digestion to the absorptive mucosa of the small intestine. In addition the high satiety effect of unrefined carbohydrate, whilst not influencing energy density, may well result in a reduction of total energy intake if this is a major energy source in the diet. The total dietary energy intake can be modified by various manoeuvres whilst maintaining adequate nutrient density, palatability and nutritional balance. Low-energy-density foods of high nutrient density and with satiating attributes can be used to reduce energy density and intake; high-nutrient-density foods can result in increased overall nutrient intake.

For therapeutic use dietary changes can be used to modify energy intake by selection of foods of appropriate energy density. In practice it is not always easy to achieve sufficient modification in dietary energy sources to obtain a short-term therapeutic effect and still provide a diet which is palatable and acceptable to the individual. In many instances it seems those requiring such dietary changes are set in their eating habits and lack flexibility or enthusiasm for change. The second option is to attempt to modify the energy density of the established diet without resorting to conspicuous change. In most clinical situations there are two requirements, first to reduce overall energy intake without reducing total nutrient availability and second to slow the rate of entry of energy into the circulation in order to optimize utilization and regulate storage. Some modification of energy utilization can be achieved by dietary manipulation. In particular the use of low-glycaemic-index foods (Jenkins et al. 1980, 1981b) and viscous non-starch polysaccharides (Jenkins \& Taylor, 1981) in the management of diabetes have been attempts to regulate the rate of energy uptake. These can be useful in a proportion of patients but require motivation and good compliance.

An alternative approach has been the use of specific inhibitors of the digestion of carbohydrate and fat as therapeutic agents. Slower digestion results in a slowed availability of the digestion products, which in turn slows absorption, reduces peak blood levels of glucose and other energy-rich substrates and smooths the blood profile resulting, it is intended, in metabolic stabilization.

Many naturally occurring substances, mostly of plant origin, have antinutrient effects 
which are usually mediated by the inhibition of digestive enzymes. Many are non-specific and irreversible enzyme poisons. However, some are specific and reversible and have been investigated for therapeutic use. Amylase inhibitors were first isolated from buckwheat malt (Chrzaszcz \& Janicki, 1933), rye (Kneen \& Sandstedt, 1943), wheatgerm flour (Kneen \& Sandstedt, 1946) and navy beans (Phaseolus vulgaris L.) (Bowman, 1945). In the next 25 years numerous others, mostly proteins or glycoproteins, were isolated. Many have been purified and studied in detail. In a classic study Puls \& Keup (1973) measured the effects of a wheat amylase inhibitor (BAY d 7791) in starch-loading tests in rats, dogs and man. Though clear pharmacological effects were obtained none of these pure amylase inhibitors have proved suitable for therapeutic use. Their biochemistry has been reviewed in detail by Buonocore et al. (1981) and their pharmacology by Puls et al. (1981). Subsequently, attention has turned away from amylase inhibitors to substances which inhibit the glucosidases of the small intestinal brush border, especially inhibitors from microbial sources. These inhibitors are of protein, polypeptide and oligosaccharide structure and have properties much more suitable for therapeutic use. They have been reviewed fully by Truscheit et al. (1981, 1988), Schmidt et al. (1977) and Puls et al. $(1977 a, b)$.

As the major energy source in most diets is carbohydrate, most effort has gone into the investigation of inhibitors of carbohydrate digestion (Puls et al. 1977a,b). There has been a parallel interest in inhibitors of fat digestion and in compounds which inhibit the digestion of both substrates (Puls et al. 1984).

\section{$\alpha$-GLUCOSIDASE $(E C 3.2 .1 .20)$ INHIBITORS}

The most successful enzyme inhibitors developed are the specific, reversible inhibitors of the small intestinal brush border and lumen $\alpha$-glycosidases. These have differing substrate specificities and inhibitory potencies which affect their therapeutic application.

Acarbose. The first glucosidase inhibitor to be developed fully was acarbose (BAY g 5421) which is isolated and purified from fermentation of Actinomycetes in culture broth containing glucose and maltose. It is a pseudotetrasaccharide but with little anti-amylase effect which is a competitive, reversible inhibitor of small intestinal brush border $\alpha$-glycosidases. Its inhibitory potency is glucoamylase $>$ sucrase $>$ maltase $>$ isomaltase (Truscheit et al. 1981). Digestion of oligosaccharides and disaccharides is slowed at the brush border resulting in slower absorption of monosaccharides and consequently a reduction in post-prandial glycaemia and a delay in the glycaemic peak (Jenkins et al. $1981 a)$

The pharmacokinetics of acarbose are interesting. It acts entirely at the small intestinal brush border and less than $2 \%$ of the dose is absorbed. It is metabolized by small intestinal and bacterial $\alpha$-amylases to give a mildly active three-ring residue and by $\beta$-amylases giving an inert two-ring residue. Some of the metabolites are found in urine (Müller \& Hillebrand, 1986; Müller, 1988).

Acarbose both lowers the post-prandial glycaemic rise and causes a dose-related lowering of plasma insulin concentration in normal subjects (Hillebrand et al. 1979a,b). The lower glycaemic rise is not entirely dose-related, probably because carbohydrate malabsorption occurs at higher doses. The lowering of plasma insulin concentration is less clear in type II diabetic patients because of their reduced insulin responses. Secondary changes in other gut hormones have been reported, particularly a reduction in 
gastric inhibitory polypeptide and a later rise in enteroglucagon (Taylor et al. 1980, 1982b; Uttenthal et al. 1986, 1987).

The reduction in glycaemic response is most marked after sucrose- and starch-loading tests with a smaller effect after maltose but there is none after lactose or glucose, therefore glucose can be used in the treatment of hypoglycaemia if necessary (Jenkins et al. 1981a). Dose response studies measuring breath hydrogen after a sucrose load showed that $50 \mathrm{mg}$ acarbose reduces the glycaemic response without significant malabsorption, $100 \mathrm{mg}$ results in $40 \%$ malabsorption and $200 \mathrm{mg}$ gives almost total loss of sucrose to the colonic microflora (Jenkins et al. 1981a; Radziuk et al. 1982). Much less malabsorption occurs after mixed meals (Jenkins \& Taylor, 1982; Taylor et al. 1982a). The recommended therapeutic dose, based on dose ranging and tolerance studies, is 50 $\mathrm{mg}$ three times per day (tds) with meals, increasing to $100 \mathrm{mg}$ tds as tolerated (Hillebrand et al. 1979a,b; Aubell et al. 1982; Hillebrand \& Boehme, 1982). A starchy, low-sucrose, high-fibre diet enhances the therapeutic effect and minimizes malabsorption (Taylor et al. 1982a) and its effectiveness is optimized if acarbose is uniformly mixed with the meal (O'Dea \& Turton, 1985).

Acarbose reduces triacylglycerol and very-low-density lipoprotein levels in healthy volunteers but does not alter cholesterol levels significantly (Homma et al. 1982). Similar results have been reported in most diabetic patient studies though there are some conflicting results (Vierhapper et al. 1981; Uttenthal et al. 1986). Animal studies have shown acarbose to cause a reduction in body-weight, usually in a dose-dependent way, but human studies in healthy controls, diabetic and obese subjects have shown no consistent results (William-Olsson, 1985). Clinical trials of acarbose are reported in more detail in Creutzfeldt $(1982,1988)$, Clissold \& Edwards (1988) and the Scrip review no. 26 (Anon, 1988).

Acarbose has shown the potential of $\alpha$-glycosidase inhibition in clinical use, particularly as an adjunct to the management of diabetes with diet and other therapy. There are still dietary constraints and the therapeutic dose range is narrow. Maximal inhibition of enzyme activity not only results in poorly tolerated flatulence, distension and osmotic diarrhoea but causes nutritional concern for both patient and clinician because of these symptoms which are the result of fermentation of malabsorbed nutrients.

Desoxynojirimycin derivatives. A family of $\alpha$-glucosidase inhibitors have been derived from 1-desoxynojirimycin which has been isolated from microbial culture but is now synthesized. The most important of these are miglitol (BAY m 1099), emiglitate (BAY o 1248) and a group of nitrogen-substituted derivatives of 1-desoxynojirimycin which are under investigation.

Miglitol is a pseudosaccharide and a potent, short-acting competitive $\alpha$-glucosidase inhibitor with greater effect on sucrase $(E C$ 3.2.1.48) and glucoamylase ( $E C$ 3.2.1.3) activities. It has some inhibitory effects on $\beta$-glucosidase but does not affect monosaccharide transport (Lembke et al. 1985). Unlike acarbose it is almost completely absorbed (Puls et al. 1984) then excreted unmetabolized in the urine (Ramsch et al. 1985). In oral sucrose- and starch-loading studies in rats, miglitol reduced post-prandial blood glucose and serum insulin release by slowing digestion with no evidence of malabsorption of carbohydrate. For both sucrose and starch the effect was dose-related. Blood glucose and serum insulin were unaffected by oral or intravenous administration of miglitol to fasted or glucose-loaded rats, indicating no direct hypoglycaemic effect (Bischoff et al. 1985). After the addition of miglitol to a high-carbohydrate diet, similar metabolic 
effects were found in diabetic rats when compared with non-diabetic controls (Madar, 1989). Miglitol does have an insulinotropic effect in the rat pancreas, reducing plasma insulin and insulin release from the perfused pancreas and also, interestingly, reducing exocrine amylase output (Goke et al. 1984). In healthy volunteers, miglitol reduced the post-prandial glycaemic rise after sucrose-, maltose- and starch-loading tests in a dose-dependent fashion, with considerable malabsorption after higher doses of miglitol given with sucrose (Taylor et al. 1986). In mixed meal studies $50 \mathrm{mg}$ tds miglitol given to volunteers did not cause any additional faecal energy loss (Holt et al. 1988). In other mixed-meal studies in volunteers, $50 \mathrm{mg}$ miglitol reduced the post-prandial blood glucose peak and also reduced the post-prandial insulin release significantly (Kennedy et al. 1987). In addition to its enzyme inhibitory effect, miglitol also reduces the blood glucose after a glucose load, suggesting an enhancement of insulin effect or a reduction in anti-insulin factors (Joubert et al. 1987). The efficacy of miglitol in enhancing diabetic control has been established in type I (Dimitriadis et al. 1988; Kennedy \& Gerich, 1988; Serrano-Rios et al. 1988; Hillmann et al. 1989) and type II diabetes (Katsilambros et al. 1986; Samad et al. 1988; Scott \& Tattersall, 1988; Heinz et al. 1989; Schnack et al. 1989). In most studies a reduction in the post-prandial glycaemic rise has been reported and in therapeutic dosage, usually $50 \mathrm{mg}$ tds, the inhibitor has been well tolerated. Some breath $\mathrm{H}_{2}$ evidence of mild malabsorption has been reported (Dimitriadis et al. 1988). Flatulence and loose stools at higher dosage levels suggest clinical evidence of malabsorption of carbohydrate (Scott \& Tattersall, 1988). Improved intermediary metabolism was not directly associated with better overall control of glycaemia (Samad et al. 1988).

Emiglitate has a similar core structure to miglitol with an extended side chain which renders it more lipophilic. It is a long-acting $\alpha$-glucosidase inhibitor with a similar profile to acarbose but is ten times more potent. It is absorbed and partially metabolized before urinary excretion. In healthy human subjects $20 \mathrm{mg}$ emiglitate completely abolished the glycaemic rise after $50 \mathrm{~g}$ sucrose and resulted in substantial malabsorption of carbohydrate as shown by breath $\mathrm{H}_{2}$ measurements. The effect on the digestion of starch and maltose was much less marked and there was no evidence of malabsorption of these two substrates after $20 \mathrm{mg}$ emiglitate. Both the reduction in glycaemic response and the degree of malabsorption after sucrose loading were dose-related and at a dose of $10 \mathrm{mg}$ and above were associated with marked symptoms of flatulence, distension and loose motions (Taylor et al. 1986). Over $12 \mathrm{~h}$ during which standard mixed meals were taken by healthy volunteers after a single dose of either 10 or $20 \mathrm{mg}$ emiglitate, there was no significant effect on post-prandial insulin, glucose or triacylglycerol responses compared with placebo. The higher dose caused significantly more adverse effects than placebo (Kennedy et al. 1987). However, in a second study in healthy subjects emiglitate reduced post-prandial glucose and insulin rises acutely but had no effect on triacylglycerol levels (Hillebrand et al. 1986). A number of studies on diabetic patients, both type I and type II, have been reported in preliminary form only. In a single day study of type I diabetics using standard test meals, post-prandial glycaemic rises were reduced and insulin requirement on a Biostator also fell (Serrano-Rios et al. 1988). One published study in type I diabetic patients treated for 1 month showed some improvement in control and a reduction in insulin requirement after a single daily dose of $40 \mathrm{mg}$ emiglitate (Dimitriadis et al. 1988). In comparative studies with miglitol, miglitol appeared to improve diabetic control more effectively and flexibly, to have a more suitable profile of inhibitory activity and to be better tolerated. 
The $\mathrm{N}$-substituted derivatives of 1-desoxynojirimycin appear to be potent inhibitors of sucrase and maltase in animal studies (Yoshikuni et al. 1988, 1989). They are at an early stage of development but seem to have potential.

Other $\alpha$-glycosidase inhibitors. A range of other inhibitors from diverse sources have been investigated. AO-128 is derived from valiolamine and has potent inhibitory effects in animals and man (Horii et al. 1986). MDL 25,637 is a new synthetic inhibitor with a wide and potent profile in preliminary studies (Rhinehart et al. 1987a). Castanospermine, which is a plant alkaloid extracted from the seeds of the Australian oak Castanospermum australe, is of particular interest. It is a potent inhibitor of rat intestinal glucosidases in vitro and prevents the glycaemic rise after sucrose loading. It inhibits most $\alpha$-glucosidases but is most effective in inhibiting sucrase. It has a long duration of action, showing continuing inhibition $4 \mathrm{~h}$ after dosing (Rhinehart et al. 1987b). In vitro studies show minimal recovery of $\alpha$-dextrinase (EC 3.2.1.10) activity after $24 \mathrm{~h}$ and only $30 \%$ recovery of sucrase activity at that time (Danzin \& Ehrhard, 1987). A multi-author letter in the Lancet drew attention to the fact that castanospermine and other plant alkaloid glucosidase inhibitors also have an effect in blocking the growth of the human immunodeficiency virus (HIV) (Tyms et al. 1987). This exciting observation has resulted in a change in the direction of development of castanospermine to anti-HIV therapy (Clumeck \& Hermans, 1988). Though it has a clear anti-HIV effect it may not be sufficiently potent to be used therapeutically without toxic effect but derivatives and related pseudosaccharide inhibitors are being investigated.

\section{AMYLASE INHIBITORS}

Despite much early work on amylase inhibitors and a resurgence of commercial interest in the early 1980 s as possible slimming agents, amylase inhibitors have been less promising than the specific $\alpha$-glucosidase inhibitors. Tendamistat (HOE 467-A) has been very thoroughly investigated and characterized. It is a single chain polypeptide of seventy-four amino acid residues which is a potent and specific inhibitor of $\alpha$-amylase (EC 3.2.1.1). Subsequently some smaller fragments of Tendamistat have been found to have similar properties. In carbohydrate-loading tests it has no effect on post-prandial glucose or insulin levels after glucose, maltose or sucrose (Vertesy et al. 1981). It has not been developed further for clinical use. Trestatin complex (Ro 9-0154) consists of basic amino sugar derivatives isolated from culture of Streptomyces dimorphogenes. The three main and three secondary components are part of a family of compounds with varying degrees of $\alpha$-amylase-inhibiting properties. In animal studies the complex appears to be an effective inhibitor of digestion of starch from various sources. In healthy volunteers and type I diabetics, it gave a dose-related reduction in post-starch glycaemia and insulin release compared with placebo and the effect was maintained over 4 weeks dosing in the diabetic subjects (Eichler et al. 1984).

\section{INHIBITORS OF LIPID ABSORPTION}

As enzyme inhibition as a therapeutic principle developed, attempts were made to find inhibitors of lipase (EC 3.1.1.3) activity which could be used to slow the uptake of triacylglycerols and the rate of chylomicron formation. Fenfluramine appears to slow the rate of fat absorption by inhibition of pancreatic lipase (Comai et al. 1978). Pluronic 
L-101 is a hydrophobic surfactant which inhibits pancreatic lipase. In animal feeding studies it reduced serum triacylglycerol levels and total body lipids with associated reduction in weight gain despite sustained food intake. There was evidence of fat malabsorption due to the inhibition of lipase activity (Comai \& Sullivan, 1980). BAY L 1442 is a polyether which inhibits lipase in vitro. It reduced serum triacylglycerol in fat-loading tests in rats and post-prandial cholesterol in cholesterol-loading tests (Sitt et al. 1980). BAY N 4605 has been better tolerated than previous compounds. It inhibits pancreatic lipase in vitro and in fat-loading tests in rats it reduced the post-prandial serum triacylglycerol concentration in a dose-dependent fashion. Radiolabelled triolein incorporation into adipose tissue was reduced by $80 \%$ by BAY N 4605 . In feeding studies in rats on standard chow it had no effect on weight gain but when the chow fat content was increased from $4 \%$ to $14 \%$ there was a significant reduction in the body-weight gain (Puls et al. 1984).

\section{INHIBITION OF CARBOHYDRATE ANDLIPID ABSORPTION}

In screening a range of desoxynojirimycin derivatives for $\alpha$-glucosidase inhibitory properties, it was found that BAY N 2920 also reduced the post-prandial serum triacylglycerol rise in fat-loading tests on rats. At a dose of $7 \mathrm{mg} / \mathrm{kg}$ the triacylglycerol rise was reduced to $50 \%$ of that in controls. The effective dose eliciting $50 \%$ maximal effect $\left(E_{50}\right)$ for sucrose loading was much lower at $0.2 \mathrm{mg} / \mathrm{kg}$ and for starch loading $0.3 \mathrm{mg} / \mathrm{kg}$. However, on a mixed diet the $\mathrm{ED}_{50}$ was reduced to $1.0 \mathrm{mg} / \mathrm{kg}$. The difference between the lipase inhibitory potency and that for sucrase or glucoamylase remains a problem. The compound is almost totally absorbed and excreted in the urine (Puls et al. 1984). Though it is well tolerated its use is limited by its differential inhibitory potency. Other compounds have been investigated but none have shown great potential. The quest for a combined inhibitor has now been redirected towards more specific inhibitors for particular clinical indications.

\section{CONCLUSIONS}

Inhibitors of carbohydrate and fat digestion have shown some potential for slowing the digestion and absorption of carbohydrate and of fat. Specific inhibitors of $\alpha$-glucosidases have a definite therapeutic value in reducing and delaying post-prandial glycaemic peaks and stabilizing blood glucose. They have been useful adjuncts in diabetic therapy and have the added advantage of normalizing serum lipid profiles in some patients. However, their therapeutic range is narrow and malabsorption can be a problem. Not only may energy be lost, but also other nutrients, resulting in nutritional deficiencies in long-term use. The $\alpha$-amylase inhibitors have been more limited in their application but were the subject of many pioneering studies. Lipase inhibitors have been shown to be able to regulate lipid profiles but can easily induce fat malabsorption with its associated nutritional problems. Combined inhibitors of glucosidases and lipases exist but are probably of no clinical value.

These inhibitors reviewed can, according to dose, alter the energy density of the diet and can regulate the availability of the substrates. They have opened up some new therapeutic approaches to the management of metabolic disease and, in the longer term, may have a place as an adjunct to the nutritional regulation of metabolism. 


\section{REFERENCES}

Anon (1988). Acarbose. Scrip New Product Review no. 26. Richmond: P.J.B. Publications.

Aubell, R., Boehme, K. \& Berchtold, P. (1982). One year acarbose treatment of diabetic outpatients. I Safety. II Efficacy. In Acarbose, effects on carbohydrate and fat metabolism, pp. 360-366 [W. Creutzfeldt, editor]. Amsterdam: Excerpta Medica.

Bischoff, H., Puls, W., Krause, H. P., Schmitt, H. \& Thomas, G. (1985). Pharmacological properties of the novel glucosidase inhibitors BAY m 1099 (miglitol) and BAY o 1248. Diabetes Research and Clinical Practice Suppl. 1, 133.

Bowman, D. E. (1945). Amylase inhibitor of navy beans. Science 102, 358-359.

Buonocore, V., Poerio, E. \& Silano, V. (1981). The chemistry and biochemistry of $\alpha$-amylase inhibitors. In Regulators of Intestinal Absorption in Obesity, Diabetes and Nutrition, vol. 1, pp. 87-101 [P. Berchtold, M. Cairella, A. Jacobelli and V. Silano, editors]. Rome: Societa Editrice Universo.

Chrzaszcz, T. \& Janicki, J. (1933). 'Sisto-Amylase', ein naturlicher Paralysator der Amylase. ('Sisto-Amylase', a natural inhibitor of amylase.) Biochemische Zeitschrift 260, 354-368.

Clissold, S. P. \& Edwards, C. (1988). Acarbose, a preliminary review of its pharmacodynamic and pharmacokinetic properties, and therapeutic potential. Drugs 35, 214-243.

Clumeck, N. \& Hermans, P. (1988). Antiviral drugs other than zidovudine and immunomodulating therapies in human immunodeficiency virus infection. An overview. American Journal of Medicine 85, 165-172.

Comai, K. \& Sullivan, A. C. (1980). Antiobesity activity of pluronic L-101. International Journal of Obesity 4, $33-42$.

Comai, K., Triscari, J. \& Sullivan, A. C. (1978). Comparative effects of amphetamine and fenfluramine on lipid biosynthesis and absorption in the rat. Biochemical Pharmacology 27, 1987-1994.

Creutzfeldt, W. (editor) (1982). In Acarbose, effects on carbohydrate and fat metabolism. Amsterdam: Excerpta Medica.

Creutzfeldt, W. (editor) (1988). In Acarbose for the Treatment of Diabetes Mellitus. Berlin: Springer-Verlag.

Danzin, C. \& Ehrhard, A. (1987). Time-dependent inhibition of sucrase and isomaltase from rat small intestine by castanospermine. Archives of Biochemistry and biophysics 257, 472-475.

Dimitriadis, G., Hatziagelaki, E., Ladas, S., Linos, A. \& Hillebrand, I. (1988). Effects of prolonged administration of two new alpha-glucosidase inhibitors on blood glucose control, insulin requirements and breath hydrogen excretion in patients with insulin dependent diabetes mellitus. European Journal of Clinical Investigation 18, 33-38.

Eichler, H. G., Korn, A., Gasic, S., Pirson, W. \& Businger, J. (1984). The effect of a new specific $\alpha$-amylase inhibitor on post-prandial glucose and insulin excursions in normal subjects and type 2 (non-insulindependent) diabetic patients. Diabetalogia 26, 278-281.

Goke, B., Fehmann, C., Folsch, U. R. \& Creutzfeldt, W. (1984). Influence of a new absorbable inhibitor of $\alpha$-glucosidase on the rat pancreas. Digestive Diseases and Sciences 29, 951.

Heinz, G., Komjati, M., Korn, A. \& Waldhaeusl, W. (1989). Reduction of post-prandial blood glucose by the alpha-glucosidase inhibitor miglitol (BAY m 1099) in type II diabetes. European Journal of Clinical Pharmacology 37, 33-36.

Hillebrand, I. \& Boehme, K. (1982). Clinical studies on acarbose during 5 years. In Acarbose, effects on carbohydrate and fat metabolism, pp. 445-450 [W. Creutzfeldt, editor]. Amsterdam: Excerpta Medica.

Hillebrand, I., Boehme, K., Frank, G., Fink, H. \& Berchtold, P. (1979a). The effects of the $\alpha$-glucosidase inhibitor BAY g 5421 (acarbose) on meal stimulated elevations of circulating glucose, insulin and triglyceride levels in man. Research in Experimental Medicine 175, 81-86.

Hillebrand, I., Boehme, K., Frank, G., Fink, H. \& Berchtold, P. (1979b). The effects of the $\alpha$-glucosidase inhibitor BAY g 5421 (acarbose) on postprandial blood glucose, serum insulin and triglyceride levels: dose time response relationships in man. Research in Experimental Medicine 175, 87-94.

Hillebrand, I., Boehme, K., Graefe, K. H. \& Wehling, K. (1986). The effect of new $\alpha$-glucosidase inhibitors on meal stimulated increases in glucose and insulin levels in man. Klinische Wochenschrift 64, 393-396.

Hillmann, R. J., Scott, M. \& Gray, R. S. (1989). Effect of alpha-glucosidase inhibition on glucose profiles in insulin dependent diabetes. Diabetes Research 10, 81-84.

Holt, P. R., Thea, D., Yang, M. Y. \& Kotler, D. P. (1988). Intestinal and metabolic responses to an alpha-glucosidase inhibitor in normal volunteers. Metabolism 37, 1163-1170.

Homma, Y., Irie, N., Yano, Y., Nakaya, N. \& Goto, Y. (1982). Changes in plasma lipoprotein levels during medication with a glucosidase hydrolase inhibitor (acarbose). Tokai Journal of Experimental and Clinical Medicine 7, 393-396. 
Horii, S., Fukase, H., Matsuo, T., Kameda, Y., Asano, N. \& Matsui, K. (1986). Synthesis and $\alpha-D-$ glucosidase inhibitory activity of $\mathrm{N}$-substituted valiolamine derivatives as potential oral antidiabetic agents. Journal of Medicinal Chemistry 29, 1038-1046.

Jenkins, D. J. A. \& Taylor, R. H. (1981). Significance of indigestible carbohydrates in the management of diabetes, hyperlipidaemia and obesity. In Regulators of Intestinal Absorption in Obesity, Diabetes and Nutrition, pp. 295-314 [P. Berchtold, M. Cairella, A. Jacobelli and V. Silano, editors]. Rome: Societa Editrice Universo.

Jenkins, D. J. A. \& Taylor, R. H. (1982). Acarbose: dosage and interactions with sugars, starch and fibre. In Acarbose, effects on carbohydrate and fat metabolism, pp. 86-96 [W. Creutzfeldt, editor]. Amsterdam: Excerpta Medica.

Jenkins, D. J. A., Taylor, R. H., Goff, D. V., Fielden, H., Misiewicz, J. J., Sarson, D. L., Bloom, S. R. \& Alberti, K. G. M. (1981a). Scope and specificity of acarbose in slowing carbohydrate absorption in man. Diabetes 30, 951-954.

Jenkins, D. J. A., Wolever, T. M. S., Taylor, R. H., Barker, H. M., Fielden, H., Baldwin, J. M., Bowling, A. C., Newman, H. C., Jenkins, A. L. \& Goff, D. V. (1981b). Glycaemic index of foods: a physiological basis for carbohydrate exchange. American Journal of Clinical Nutrition 34, 362-366.

Jenkins, D. J. A., Wolever, T. M. S., Taylor, R. H., Ghafari, H., Jenkins, A. L., Barker, H. M. \& Jenkins, M. J. A. (1980). Rate of digestion of foods and post-prandial glycaemia in normal and diabetic subjects. British Medical Journal 281, 14-17.

Joubert, P. H., Foukaridis, G. N. \& Bopape, M. J. (1987). Miglitol may have a blood glucose lowering effect unrelated to inhibition of alpha glucosidase. European Journal of Clinical Pharmacology 31, 723-724.

Katsilambros, N., Philippides, P., Toskas, A., Protopapas, J., Frangaki, D., Marangos, M., Siskoudis, P., Anastasopoulou, K., Xefteri, H. \& Hillebrand, I. (1986). A double-blind study on the efficacy and tolerance of a new alpha-glucosidase inhibitor in type 2 diabetics. Arzneimittelforschung 36, 1136-1138.

Kennedy, F. P. \& Gerich, J. E. (1988). Alpha-glucosidase inhibition and timing of pre-prandial insulin in patients with insulin-dependent diabetes mellitus. Diabetes Research and Clinical Practice 4, 309-312.

Kennedy, F. P., Miles, J. M., Heiling, V. \& Gerich, J. E. (1987). The effect of two new $\alpha$-glucosidase inhibitors on metabolic responses to a mixed meal in normal volunteers. Clinical and Experimental Pharmacology and Physiology 14, 633-640.

Kneen, E. \& Sandstedt, R. M. (1943). An amylase inhibitor from certain cereals. Journal of the American Chemical Society $65,1247$.

Kneen, E. \& Sandstedt, R. M. (1946). Distribution and general properties of an amylase inhibitor in cereals. Archives of Biochemistry 9, 235-249.

Lembke, B., Foelsch, U. R. \& Creutzfeldt, W. (1985). Effect of 1-desoxynojirimycin derivatives on small intestinal disaccharidase activities and on active transport in vitro. Digestion 31, 109-116.

Madar, Z. (1989). Metabolic consequence of the alpha-glucosidase inhibitor BAY m 1099 given to non-diabetic and diabetic rats fed a high-carbohydrate diet. American Journal of Clinical Nutrition 49, 106-111.

Müller, F. O. (1988). The pharmacokinetics of acarbose in humans. In Acarbose for the Treatment of Diabetes Mellitus, pp. 17-24 [W. Creutzfeldt, editor]. Berlin: Springer-Verlag.

Müller, F. O. \& Hillebrand, I. (1986). Acarbose (BAY g 5421) kinetics in healthy volunteers. Acta Pharmacologica et Toxicologica 59, Suppl. V, 303.

O'Dea, K. \& Turton, J. (1985). Optimum effectiveness of intestinal $\alpha$-glucosidase inhibitors: importance of uniform distribution through a meal. American Journal of Clinical Nutrition 41, 511-516.

Puls, W. \& Keup, U. (1973). Influence of an $\alpha$-amylase inhibitor (BAY d 7791) on blood glucose, serum insulin and NEFA in starch loading tests in rats, dogs and man. Diabetologia 9, 97-101.

Puls, W., Keup, U., Krause, H. P., O'Dea, K. \& Sitt, R. (1981). Pharmacological significance of alpha-amylase inhibitors. In Regulators of Intestinal Absorption in Obesity, Diabetes and Nutrition, vol. 1, pp. 153-179 [P. Berchtold, M. Cairella, A. Jacobelli and V. Silano, editors]. Rome: Societa Editrice Universo.

Puls, W., Keup, U., Krause, H. P. \& Thomas, G. (1977a). Glucosidase inhibition: a new approach to the treatment of carbohydrate dependent metabolic disorders. Diabetologia 13, 426.

Puls, W., Keup, U., Krause, H. P., Thomas, G. \& Hoffmeister, F. (1977b). Glucosidase inhibition: a new approach to the treatment of diabetes, obesity and hyperlipoproteinaemia. Naturwissenschaften 64, 536.

Puls, W., Krause, H. P., Muller, L., Schutt, H., Sitt, R. \& Thomas, G. (1984). Inhibitors of the rate of carbohydrate and lipid absorption by the intestine. International Journal of Obesity 8, Suppl, 1, 181-190. 
Radziuk, J., Kemmer, F., Berchtold, P. \& Vranic, M. (1982). Quantitation of the effects of the $\alpha$-glucosidase inhibitor acarbose on the hydrolysis and absorption of sucrose and hormone responses in man. In Acarbose, effects on carbohydrate and fat metabolism, pp. 113-122 [W. Creutzfeldt, editor]. Amsterdam: Excerpta Medica.

Ramsch, K. D., Wetzelsberger, N., Putter, J. \& Maul, W. (1985). Pharmacokinetics and metabolism of the desoxynojirimycin derivatives BAY m 1099 and BAY o 1248. Diabetes Research and Clinical Practice Suppl. 1, 1199.

Rhinehart, B. L., Robinson, K. M., Liu, P. S., Payne, A. J., Wheatley, M. E. \& Wagner, S. R. (1987a). Inhibition of intestinal disaccharidases and suppression of blood glucose by a new $\alpha$-glucohydrolase inhibitor - MDL 25, 637. Journal of Pharmacology and Experimental Therapeutics 241, 915-920.

Rhinehart, B. L., Robinson, K. M., Payne, A. J., Wheatley, M. E., Fisher, J. L., Liu, P. S. \& Cheng, W. $(1987 b)$. Castanospermine blocks the hyperglycaemic response to carbohydrates in vivo: a result of intestinal disaccharidase inhibition. Life Sciences 41, 2325-2331.

Samad, A. H., Willing, T. S., Alberti, K. G. \& Taylor, R. (1988). Effects of BAY m 1099, a new alpha-glucosidase inhibitor, on acute metabolic responses and metabolic control in non-insulin dependent diabetes mellitus over one month. Diabetes Care 11, 337-344.

Schmidt, D. D., Frommer, W., Junge, B., Müller, L., Wingender, W., Truscheit, E. \& Schafer, D. (1977). $\alpha$-glucosidase inhibitors: new complex oligosaccharides of microbial origin. Naturwissenschaften 64, $535-536$.

Schnack, C., Prager, R. J., Winkler, J., Klauser, R. M. \& Schneider, B. G. (1989). Effects of 8-week alpha-glucosidase inhibition on metabolic control, C-peptide secretion, hepatic glucose output, and peripheral insulin sensitivity in poorly controlled type II diabetic patients. Diabetes Care 12, 537-543.

Scott, A. R. \& Tattersall, R. B. (1988). Alpha glucosidase inhibition in the treatment of non-insulin-dependent diabetes mellitus. Diabetic Medicine 5, 42-46.

Serrano-Rios, M., Saban, J., Navascues, I., Canizo, J. F. \& Hillebrand, I. (1988). Effect of two new alpha-glucosidase inhibitors in insulin-dependent diabetic patients. Diabetes Research and Clinical Practice 4, 111-116.

Sitt, R., Krause, H. P., Puls, W., Steinert, G. \& Horstmann, H. (1980). Inhibition of cholesterol and triglyceride absorption. VIIth International Symposium on Drugs Affecting Lipid Metabolism, p. 80. Milano: Fondazione G. Lorenzini.

Taylor, R. H., Barker, H. M., Bowey, E. A. \& Canfield, J. E. (1986). Regulation of the absorption of dietary carbohydrate in man by two new glucosidase inhibitors. Gut 27, 1471-1478.

Taylor, R. H., Jenkins, D. J. A., Barker, H. M., Fielden, H., Goff, D. V., Misiewicz, J. J., Lee, D. A., Allen, B., McDonald, G. \& Wallrabe, H. (1982a). Effect of acarbose on the 24-hour blood glucose profile and pattern of carbohydrate absorption. Diabetes Care 5, 92-96.

Taylor, R. H., Jenkins, D. J. A., Goff, D. V., Bloom, S. R., Sarson, D. L., Misiewicz, J. J. \& Alberti, K. G. M. M. (1982b). Gut hormone response to carbohydrate with acarbose and guar. In Acarbose, effects on carbohydrate and fat metabolism, pp. 206-209 [W. Creutzfeldt, editor]. Amsterdam: Excerpta Medica.

Taylor, R. H., Jenkins, D. J. A., Goff, D. V., Nineham, R., Bloom, S. R. \& Sarson, D. (1980). Enteroglucagon release stimulated by carbohydrate malabsorption: a clue to its physiological role? $G$ ut 21 , 449.

Truscheit, E., Frommer, W., Junge, B., Müller, L., Schmidt, D. D. \& Wingender, W. (1981). Chemistry and Biochemistry of microbial $\alpha$-glucosidase inhibitors. Angewandte Chemike 20, 744-761.

Truscheit, E., Hillebrand, I., Junge, B., Müller, L., Puls, W. \& Schmidt, D. (1988). Microbial $\alpha$-glucosidase inhibitors: chemistry, biochemistry and therapeutic potential. Progress in Clinical Biochemistry 7, 17-99.

Tyms, A. S., Berrie, E. M., Ryder, T. A., Nash, R. J., Hegarty, M. P., Taylor, D. L., Mobberley, M. A., Davis, J. M., Bell, E. A., Jeffries, D. J., Taylor-Robinson, D. \& Fellows, L. E. (1987). Castanospermine and other plant alkaloid inhibitors of glucosidase activity block the growth of HIV. Lancet ii, 1025-1026.

Uttenthal, L. O., Ukponmwan, O. O., Wood, S. M., Ghiglione, M., Ghatei, M. A., Trayner, I. M. \& Bloom, S. R. (1986). Long-term effects of intestinal alpha-glucosidase inhibition on post-prandial glucose, pancreatic and gut hormone responses and fasting serum lipids in diabetics and sulphonylureas. Diabetic Medicine 3, 155-160.

Uttenthal, L. O., Ukponmwan, O. O., Ghiglione, M. \& Bloom, S. R. (1987). Acute and short term effects of intestinal alpha-glucosidase inhibition on gut hormone responses in man. Digestive Diseases and Sciences 32, 139-144. 
Vertesy, L., Oeding, V., Bender, R., Nesemann, G., Sukatsch, D. \& Zepf, K. (1981). Chemistry and biochemistry of a novel alpha-amylase inactivator HOE 467 from Str. tendae. In Regulators of Intestinal Absorption in Obesity, Diabetes and Nutrition, vol. 2, pp. 269-274 [P. Berchtold, M. Cairella, A. Jacobelli and V. Silano, editors]. Rome: Societa Editrice Universo.

Vierhapper, H., Bratusch-Marrain, P. \& Waldhausl, W. (1981). Long term treatment of sulphonylurea-treated diabetics with the alpha-glucosidase inhibitor BAY g 5421 (acarbose). Diabetalogia $20,586$.

William-Olsson, T. (1985). $\alpha$-glucosidase inhibition in obesity. Acta Medica Scandinavica 706, Suppl., 1-39.

Yoshikuni, Y., Ezure, Y., Aoyagi, Y. \& Enomoto, H. (1988). Inhibition of intestinal $\alpha$-glucosidase and postprandial hyperglycaemia by $\mathrm{N}$-substituted moranoline derivatives. Journal of Pharmacobia-Dynamics 11, 356-362.

Yoshikuni, Y., Ezure, Y., Seto, T., Mori, K., Watanabe, M. \& Enomoto, H. (1989). Synthesis and $\alpha$-glucosidase-inhibiting activity of a new alpha-glucosidase inhibitor, 4-0-alpha-D-glucopyranosylmoranoline and its N-substituted derivatives. Chemical and Pharmaceutical Bulletin 37, 106-109. 